counsellor who will spend much time comforting patients after traumatic events. I suggest that general practitioners used to have the leisure to do this but are no longer able to do so, as their time is used up in dealing with surgery consultations, social security assessments, health promotion activities, public health measures, devolved secondary care, community care, and NHS administration.

The deputy was probably seeing a variety of "emergencies"-mostly cases of self limiting illness in fit people. Deputies are experts at this type of general practice. They are not experts in resuscitation or counsellors, they cannot stay and comfort bereaved people for long; they have to be off to the next sore throat.

Had Rawlinson's neighbour had access to an out of hours emergency centre she would have travelled quickly and received prompt care from fresh staff trained in emergency care; her husband could have contacted a counsellor or, perhaps more appropriately, a minister of religion, friend, or neighbour in his bereavement. A social worker might have organised his social care needs. Surely this is preferable to the current system, whereby society prefers the false belief that everything could be delivered by one's own general practitioner if only he or she attended.

I work 80 hours a week. My reserves of care and compassion are regularly exhausted. I send deputies to people who I believe are going to use up more of myself than I and the rest of my patients can afford. A bereaved relative told me today that was a wonderful doctor, but I doubt if I will be doing the same job after the age of 45 . The personal service that Rawlinson and Rawlinson's neighbour yearn for is delivered only at terrible cost to genera practitioners and their families. The time has come to acknowledge this and change to a better system.

FAY WILSON

Birmingham B10 9QX General practitioner

1 Rawlinson JN. Deputising general practitioners' role in emergencies. $B M F$ 1995;311:394. (5 August.)

\section{Treatment of acute anaphylaxis}

\section{Surviving the journey is a good prognostic indicator}

EDrToR,-Malcolm Fisher's article on acute anaphylaxis was prompted by an anecdote concerning a doctor's panic when his young daughter developed an acute allergic reaction.' The father ended up "ranting and raving" in the emergency department because his daughter had not received adrenaline immediately. Fisher uses this scenario to underline the need for the rapid administration of adrenaline in anaphylaxis. Nevertheless, he freely admits that, with the protean and sometime life threatening nature of anaphylaxis and anaphylactoid reactions, randomised controlled trials of treatment are not feasible.

Given the emotive and anecdotal origin of Fisher's article, it is perhaps important to be aware of other anecdotal issues in the treatmen of anaphylaxis. Each year we admit roughly 100 patients with acute allergic reactions of the sort described in Fisher's article to our short stay observation ward; a minority of these patients receive adrenaline, but the overwhelming majority are fit for discharge within 24 hours. The patients typically receive nebulised salbutamol, parenteral or oral steroid, and parenteral antihistamine. The problems that we encounter are usually those of rebound or biphasic systemic anaphylaxis (in about $7 \%$ ), which merits treatment with ora antihistamine and steroid for about two days. ${ }^{2}$

Just like the doctor described in Fisher's article, I too received the fright of my life once, only my fright was induced by adrenaline during dentistry.
Adrenaline is as toxic as any drug: it can cause dangerous arrhythmias and profound distress in lucid patients. My thesis is that most unheralded deaths from uniphasic anaphylaxis occur within a few minutes of exposure and that those patients who survive to reach the emergency department are effectively in a separate category: observation over a few minutes or an experienced doctor can identify that minority requiring aggressive treatment with adrenaline. This may be a dangerous and heretical theory based on anecdote, but I believe that the universal prescription of adrenaline suggested in all contemporary texts is equally anecdotal and warrants closer examination. I accept that adrenaline is the drug of first choice in life threatening anaphylaxis, but I do not believe that all urticarial, angio-oedematous, or bronchospastic reactions are potentially lethal. The story in Fisher's article is important, but the girl survived: nearly all patients do, with precisely the treatment she received.

Consultant in accident and emergency medicine

Royal Liverpool and

Broadgreen University Hospitals NHS Trust,

Liverpool L7 8XP

1 Fisher M. Treatment of acute anaphylaxis. BMF 1995;311: 731-3. (16 September.)

Douglas DM, Sukenick E, Andrade WP, Brown JS. Biphasic systemic anaphylaxis: an inpatient and outpatient study. f Allergy Clin Immunol 1994;93:977-85.

\section{Remove the patient from contact with the allergen}

EDITOR,-In his article on the treatment of acute anaphylaxis Malcolm Fisher omits one important point: that further contact with the allergen should be prevented immediately. In the case of stings or intramuscular injections a tourniquet should be applied proximal to the site; bee stings should be removed, and any drugs being given intravenously at the time that anaphylaxis occurred should be stopped. Food allergens should be removed from the mouth, and if the patient is still conscious the mouth may be rinsed. Vomiting of recently ingested food can also be induced by putting two fingers in the throat of patients who are still alert and realise that they have swallowed something to which they are very allergic.

As with other allergic diseases, such as asthma and rhinitis, the efficacy of avoiding the relevant allergen should not be underestimated.

GLENIS K SCADDING Consultant physician in clinical immunology, allergy, and rhinology

Royal National Throat, Nose and Ear Hospital, London WC1X 8DA

1 Fisher M. Treatment of acute anaphylaxis. BMF 1995;311: 731-3. (16 September.)

\section{Benign allergic reactions should not be treated with adrenaline}

EDrTOR,-The case report of an anaphylactic reaction, presumably to nuts, and Malcolm Fisher's review of anaphylaxis and its treatment are timely. The management of children's anaphylactic reactions to foods has recently been reviewed, ${ }^{23}$ and our experience in childhood allergy-in particular, peanut allergy-prompts us to emphasise some additional points and to urge clarification of terminology.

Fatal and near fatal anaphylaxis related to foods most commonly occurs in patients who have had previous severe reactions, which makes the history crucial rather than "of little value," as Fisher seems to suggest. ${ }^{1}$ A high risk of anaphylaxis related to food is associated with poorly controlled asthma and the requirement of oral corticosteroids and with delay in the administration of adrenaline. ${ }^{4}$

Doctors who may encounter an anaphylactic emergency must be aware that $\beta$ blocking drugs may potentiate anaphylaxis ${ }^{5}$ and that fatal and near fatal reactions to foods sometimes proceed in the absence of signs of more minor reactions-for example, collapse and cyanosis without urticaria or pruritus. ${ }^{4}$ This again emphasises the importance of the history and awareness of allergy on the part of the subject, care givers, teachers, and doctors.

Patients often come to us with a diagnosis of anaphylaxis only for us to find that the reaction was confined to urticaria of short duration after exposure to a large dose of allergen. To label this benign reaction as anaphylaxis is misleading and alarmist: it may render the subject vulnerable to being overtreated (with adrenaline) when reassurance and observation or an antihistamine would suffice. We accept that the converse also applies with regard to the misdiagnosis of compromise of the airway or hypotension as a mild allergic reaction to be treated with antihistamines. Nevertheless, we urge that the term anaphylaxis be restricted to catastrophic, life threatening allergic reactions and accurate terms for urticaria, mild angio-oedema, and laryngeal oedema be used. Laryngeal oedema is, of course, life threatening and requires treatment with inhaled or injected adrenaline.

JONATHAN O'B HOURIHANE Clinical research fellow JOHN O WARNER

School of Medicine,

Child Health,

Southampton General Hospital,

Southampton SO16 6YD

Fisher M. Treatment of acute anaphylaxis. BMF 1995;311: 731-3. (16 September.)

2 Patel L, Radivan FS, David TJ. Management of anaphylactic reactions to food. Arch Dis Child 1994;71:370-5.

3 Hourihane JO'B, Warner JO. Management of anaphylactic reactions to foods. Arch Dis Child 1995;72:274.

4 Sampson HA, Mendelson L, Rosen JP. Fatal and near fatal anaphylactic reactions to food in children and adolescents. N Engl f Med 1992;327:380-4.

5 Jacobs RL, Rake GW, Fournier DC, Chilton RJ, Culver WG, Beckmann $\mathrm{CH}$. Potentiated anaphylaxis in patients with druginduced beta-adrenergic blockade. $\boldsymbol{f}$ Allergy Clin Immunol 1981;68:125-7.

\section{Avoid subcutaneous or intramuscular adrenaline}

EDrToR,-Malcolm Fisher states that intravenous adrenaline should be used only in severe cases of anaphylaxis as it may cause arrhythmias ${ }^{1}$ and cites a publication by Waldhausen et al..$^{2}$ In this paper the doses given intravenously were up to 20 times the initial dose recommended by the Association of Anaesthetists of Great Britain and Ireland. Previous authors have also expressed misgivings about using intravenous adrenaline on the basis of anecdotal reports in which the speed of administration was not stated and other causes of arrhythmias were not excluded. ${ }^{4}$ Like any other drug, adrenaline may be dangerous if given too fast or in an excessive dose, but it is illogical to restrict its use because of concerns over complications caused by inappropriate administration.

Ideally, intravenous adrenaline should be the first line treatment for all patients with anaphylaxis treated by medically trained staff. It is safe and effective if given in a controlled titrated manner at an initial dose of $0.5-1 \mathrm{ml}$ of $1 / 10000$ solution. This ensures rapid delivery to its site of action and avoids the problem of variable absorption after its administration subcutaneously or intramuscularly in patients in whom tissue perfusion may be compromised. In addition to treating the pathological vasodilatation that contributes to hypotension in anaphylaxis, adrenaline stabilises mast cells and therefore treats both the effect and the cause of the condition when distributed systemically.

In a child with anaphylaxis, difficulty in securing venous access should not be regarded as an impediment to the use of adrenaline by infusion. As recommended by advanced paediatric life support 
teaching, intraosseous access may be secured without difficulty and should be considered in any paediatric emergency in which intravenous acces cannot be secured promptly. Bolus and infusion doses of adrenaline can be given safely by this route, as can other pharmacological agents recommended in anaphylaxis.

In children with signs of upper airway obstruction caused by laryngeal mucosal oedema, nebulised adrenaline may lead to prompt resolution of stridor. ${ }^{5}$ It should be given as a dose of either $0.05 \mathrm{ml}$ of a $2.25 \%$ (racemic) solution $/ \mathrm{kg}$ diluted to $2 \mathrm{ml}$ with normal saline or, more conveniently, as $0.5 \mathrm{ml}$ of a $1 / 1000$ solution $/ \mathrm{kg}$ (to a maximum of $5 \mathrm{ml}$ ). The child whose clinical history prompted Fisher's review would probably have benefited from this treatment.

Finally, in both his article and the summary in "This week in BMF" Fisher states that oxygen should be given in severe anaphylaxis. We prefer the recommendations of the Association of Anaesthetists of Great Britain and Ireland that oxygen should be given in all cases of anaphylaxis regardless of the initial severity. ${ }^{3}$ Hypoxaemia will develop quickly if a patient suddenly develops airway obstruction as a late complication of an initially mild attack.

R ALEXANDER Senior registrar in anaesthes J PAPPACHAN Senior registrar in intensive care G B SMITH

Director of intensive care B L TAYLOR

Consultant in intensive care and anaesthesia Department of Intensive Care Medicine, Queen Alexandra Hospital,

Cosham,

Portsmouth PO6 3LY

1 Fisher M. Treatment of acute anaphylaxis. BMF 1995;311 731-3. (16 September)

2 Wauldhausen E, Keser G, Marquadt B. Der Anaphlaktishe Shock [Anaphylactic shock]. Anaesthetist 1987;36:150-8.

3 Association of Anesthetists of Great Britain and Ireland. Anaphylactic reactions associated with anaesthesia. London: AAGBI, 1990.

4 Roberts-Thompson P, Hewddle R, Kupa A. Adrenaline and anaphylaxis. Med $\mathcal{F}$ Aust 1985;142:708.

Jordan WS, Graves CL, Elwyn RA. New therapy for pos intubation laryngeal edema and tracheitis in children. $¥ A M A$ 1970;212:585-8.

\section{Expressing the dose of adrenaline in milligrams is easier}

EDITOR,-In his article on the treatment of ana phylaxis Malcolm Fisher emphasises the role of adrenaline. ${ }^{1}$ The dose that he recommends is expressed as two volumes of two solutions of differing concentration. Quoting a dose in this way increases confusion and makes the dose less memorable-which may partly explain why the doctor described in the introductory letter "fumbles through pages of a book to figure out adrenaline dosage."

The revised guidelines of the European Resuscitation Council's working party now express the adrenaline dose in milligrams, and this has both simplified resuscitation algorithms and made them more memorable. ${ }^{2}$ This has been complemented by the availability of adrenaline in rapid assembly preloaded syringes of $1 \mathrm{mg}(10 \mathrm{ml}$ of $1 / 10000)$ (Min-I-Jet). Although these syringes are currently recommended by the manufacturers for only intravenous or intracardiac use, they will readily accept a 21 gauge syringe and could therefore also deliver an intramuscular dose.

If the recommended dose of adrenaline was expressed in milligrams and delivered by a pre loaded syringe the correct treatment of anaphylaxis would be swifter, simpler, and easier to remember.
1 Fisher M. Treatment of acute anaphylaxis. BMF 1995;311: 731-3. (16 September.)

European Resuscitation Council Working Party. Adult advanced cardiac life support: the ERC guidelines (abridged). BMF 1993;306:1589-93.

\section{Treatment takes precedence over} monitoring

EDITOR,-We believe that the ability to start immediate and effective treatment for acute anaphylactic shock is an essential skill for any medical practitioner. Unfortunately, Malcolm Fisher may have caused confusion with his recommendations for the use of intravenous adrenaline. ${ }^{1}$ Fisher contradicts himself by stating that intravenous adrenaline should not be given to an "unmonitored patient" and then subsequently recommends its use in this very situation. We agree that early placement of cardiorespiratory monitoring devices is essential in any severe anaphylactic episode but would strongly urge that the administration of intravenous adrenaline should not be deferred until such equipment is available. In its recommendations for the management of anaphylactoid reactions the Association of Anaesthetists of Great Britain and Ireland emphasises the need for early administration of adrenaline intravenously. ${ }^{2}$

With regard to the management of bronchospasm, we agree that inhalation of the volatile anaesthetic agent isoflurane may have a role but would suggest that halothane, which has more potent effects as a bronchodilator, is more appropriate. $^{3}$ Numerous reports describe the use of inhaled and nebulised adrenaline solutions in life threatening acute upper and lower airway obstruction caused by anaphylaxis. ${ }^{45} \mathrm{We}$ are therefore surprised that this accepted therapeutic regimen is omitted from the recommended treatment protocols for bronchospasm and angiooedema.

JOHN CLEAR Senior registrar MICHAEL YEOH Senior house officer STEPHEN COCKROFT Consultant

Anaesthetic Department, Salisbury District Hospital, Salisbury SP2 8B]

1 Fisher M. Treatment of acute anaphylaxis. BMF 1995;311: 731-3. (16 September.)

2 Association of Anaesthetists of Great Britain and Ireland. Anaphylactic reactions associated with anaesthesia. London: AAGBI, 1990

3 Calvey TN, Williams NE. Principles and practice of pharmacology for anaesthetists. Oxford: Blackwell, 1991.

McConachie I. Laryngeal oedema following anaphylactic shock. BfHM 1992;47:201.

5 Muller U, Mosbech H, Blaauw P, Dreborg S, Malling HJ, Przybilla B, et al. Emergency treatment of allergic reactions to Przybilla B, et al. Emergency treatment of allergic react

\section{Investigations help to confirm diagnosis}

EDITOR,-Malcolm Fisher's review highlights the need for adrenaline along with volume replacement in the management of severe systemic anaphylaxis. ${ }^{1}$ This observation was recognised by the Association of Anaesthetists of Great Britain and Ireland, which in 1990 produced a booklet for all members ${ }^{2}$ and a wall chart for the theatre area.

As Fisher states, cardiovascular collapse is a common feature of anaphylaxis, but, particularly in the context of surgery, it is not the only diagnosis that has to be considered: myocardial infarction, pulmonary embolus, and concealed hypovolaemia are some of the diagnoses that have to be excluded. The diagnosis may be unclear, especially if the patient dies. Furthermore, the management of an acute systemic anaphylaxis is stressful. Information is often not readily available about which investigations to carry out or what to do with samples, so blood tests can be spoiled or results
After resuscitation carry out the following:

\section{Blood tests}

Take $20 \mathrm{ml}$ of blood for mast cell tryptase, specific IgE antibodies, and complement at 1,3 and approximately 8 hours after the suspected reaction.

\section{Bottle as follows:}

$10 \mathrm{ml}$ in an activated gel bottle (speckled top) for serum and $5 \mathrm{ml}$ in each of two edetic acid (EDTA) (full blood count) bottles. Label the form correctly. Send to the department of immunology in Southmead. If outside laboratory hours inform the haematologist, who will separate the serum and, if necessary, store it at $-20^{\circ} \mathrm{C}$. The samples must be processed as soon as possible, but they need not be sent to immunology out of hours.

\section{Part of follow up card for anaphylaxis}

misplaced. The relevant history and clinical signs may not be documented. To combat these shortcomings a plastic laminated action card has been written, which is placed in the operating theatres of the hospitals in Bristol. It describes in simple terms how to investigate a case of suspected anaphylaxis (figure).

Requests are made for full details from a checklist, including history of allergies; use of latex (urinary catheter or sterile gloves); treatment with antibiotics, colloid, and blood; date, time, and severity of reaction; etc. The action card instructs the attending anaesthetist to pass the patient's details to a designated consultant anaesthetist, who has an interest in anaphylaxis and who then refers the patient to the immunologist.

Assay of serum mast cell tryptase is helpful in the follow up. ${ }^{34}$ Tryptase is liberated along with histamine from mast cells when they degranulate. Furthermore, unlike histamine, it is stable in blood. If tryptase is increased then mast cells have been degranulated. It has also been assayed after death, which could be important medicolegally. ${ }^{4}$ Specific IgE is also helpful in this respect, a view shared by Laroche et al.

Immunologists from other regions may disagree with the investigations or the timing of the samples as written in the extract from our follow up card Nevertheless, the instructions have increased the amount of useful information for the immunologists and have enabled suspected systemic anaphylaxis to be diagnosed and more fully investigated.

M ROBINSON

Department of Anaesthesia,

Bristol BS16 1LE

1 Fisher M. Treatment of acute anaphylaxis. BMF 1995;311: 731-3. (16 September)

2 Association of Anaesthetists of Great Britan and Ireland. Anaphylactic reactions associated with anaesthesia. London AAGBI, 1990.

3 Tanus T, Mines D, Atkins PC, Levinson AI. Serum tryptase in idiopathic anaphylaxis: a case report and review of the literature. Ann Emerg Med 1994;24:104-7.

4 Ansari MQ, Zamora JL, Lipscomb MF. Postmortem diagnosis of acute anaphylaxis by serum tryptase analysis. A case repor Am F Clin Pathol 1993;99:101-3.

5 Laroche D, Lefrancois C, Gerard JL, Dubois F, Vergnaud MC, Gueant JL, et al. Early diagnosis of anaphylactic reactions to neuromuscular blocking drugs. Br f Anaesth 1992;69:61 1-4

\section{Chart helps with calculation of dose of adrenaline for children}

EDITOR,-In the report of a case of anaphylaxis that prompted Malcolm Fisher's review the casualty officer had difficulty in determining the correct dose of adrenaline for a 5 year old child. ${ }^{1}$ Fisher recommends $0.01 \mathrm{ml}$ of $1 / 1000$ adrenaline solution $\mathrm{kg}$ by intramuscular injection or $0.1 \mathrm{ml}$ of $1 / 10000$ solution $/ \mathrm{kg}$ intravenously. This advice would not have helped the attending doctor to check the 